\title{
局所移動座標の選択が平面骨組の有限変位解析の 精度に及ぼす影響 \\ ON THE CHOICE OF LOCAL MOVING COORDINATES IN THE FINITE DISPLACEMENT ANALYSIS OF PLANE FRAMES
}

\author{
後 藤 芳 顯* ·春日井俊博** ・西 野文 雄*** \\ By Yoshiaki GOTO, Toshihiro KASUGAI and Fumio NISHINO
}

\begin{abstract}
The method with the separation of rigid body displacements is most commonly used in the finite displacement analysis of structures. This method introduces local moving coordinates in order to remove the rigid body rotations of respective finite elements. The local coordinates utilized in the analysis of plane frames are classified into two kinds and the choice of the local coordinates is known to have an effect on the accuracy and the convergence of the solutions.

This paper precicely examines the theoretical effect of local coordinates on the accuracy of the finite displacement analysis for plane frames.

Keywords : finite displacement analysis, plane frame, accuracy
\end{abstract}

\section{1. まえがき}

構造物の有限変位解析において多く用いられる 用体変位除去の手法は, Total Lagrange の手法 に比へ，離散化解析の定式化が比較的容易で，し かも，大きな変位挙動まで追跡し得るので，実用 的な解析では最も多く用いられる. その反面，剛 体変位除去の手法では, 用体回転を除去した後の, 回転成分が小さいという物理的考察に基づき，局 所系での支配方程式の簡略化がなされるため，そ の精度のみならず, 理論的根拠については, 従来 必ずしも明らかでなかった注1).

著者らは, 䍑体変位除去の手法による効率的な計算を 行うための指針を提示することを目的として，それらの 問題を収束性ならびに, 精度の観点から初めて理論的に 明らかにし(1) -3), この理論的検討の妥当性も, 精密な数

* 正会員 工博 名古屋工業大学助教授 工学部社会開発 工学科 ( 7466 名古屋市昭和区御器所町)

** 学生会員 名古屋工業大学大学院 博士前期課程社会開 発工学専攻 (同上)

*** 正会員 Ph. D. 東京大学教授 工学部土木工学科 ( (113 文京区本郷)

注 1 ) 平面骨組の各種有限変位解析法に対する解説と参考文 献は文献 1 ) に詳述されている.

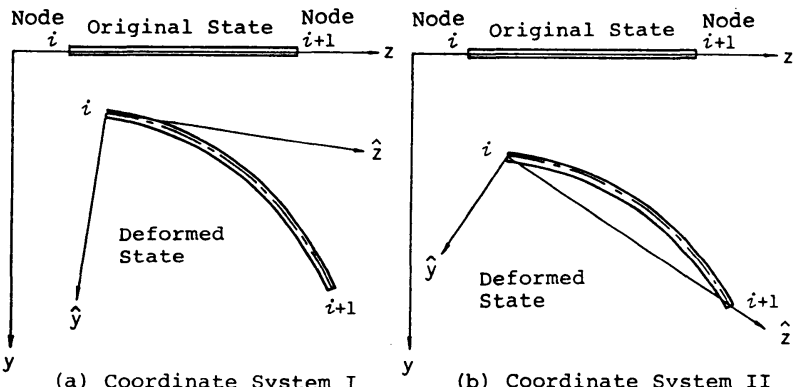

Fig. 1 Local Moving Coordinate Systems of a Beam Element.

値計算によって調べてきだ). また，著者らの研究に続 き, 剛体変位除去の手法の収束性のみに関しては, 若干 の研究5)がなされている.ここでは，ひずみエネルギー の観点から, 要素接線㣚性の対称性を保持しつつ, 䣓体 変位除去の手法が収束するための条件が論じられてい る.

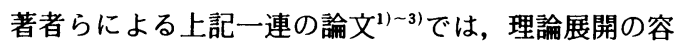
易さから,Fig. 1 (a) に示すように, 局所座標系の $\hat{z}$ 軸を $i$ 節点における変形後の要素軸接線方向に選ぶ場合 に限定しており，実際の解析で最も多く用いられるより 一般的な Fig. 1 (b) のような, 変形後の $i$ 節点と $i+1$ 節点を結ぶ割線方向に $\hat{z}$ 軸を選ぶ場合の精度について 
は，いまだ十分に検討されていない.

本論文では，より実際に促した精度を明らかにするこ とを目的として,Fig.1 (b) の局所座標系 II を採用し た場合の剛体変位除去の手法の精度を Lagrange 表現の 高次非線形微分方程式の解との比較において, 理論的に 検討する.さらに, 上記の検討に，局所座標系 I に関し てすでに得られている結果 ${ }^{1)} に$ 若干追加したものを含 め, 実用的な解析に用いられる䍑体変位除去の手法の基 本的な精度特性を総合的に調へ，効率的な計算を実施す るための指針を明らかにするものである.なお，文献 1) 〜4) では, 並進ならびに回転変位, 断面モーメント, 空間固定座標方向の節点力の精度を示し, 軸力およびせ ん断力の精度については明示していないが，文献 6 ）の 討議に述へらられているように，これらの諸量も設計上重 要であることから，ここでは検討に加える.

\section{2. 検 討 内 容}

剛体変位除去の手法では, 局所座標系の差のほかに用 体変位除去後の局所系の支配方程式や剖体回転除去後の 回転角の評価式の差により各種定式化が報告されてい る.ここでは, 重要なものということで, Table 1 に示 す 4 種類の局所系の支配方程式, さらに, Table 2 に示 す 3 種類の剛体回転除去後の回転角評価式について, そ
れぞれの差が局所座標系 II のもとで, 解析精度に及ぼす 影響について検討する.これらの，精度評価の基準とし ては, 先の論文 ${ }^{1)} と$ 同様, Table 3 に示す Lagrange 表現 の高次非線形支配方程式の解を用いる.

Table 1 の局所系の支配方程式のうち, c) 線形化は り・柱の式は，b）はり・柱の式の軸力-変位関係式に おいて, 変位の非線形項を無視したものである.この式 は，文献 1 ) では理論的検討に含めていないが，実際の 解析では比較的多く用いられるため, 新たに検討対象と する. また，d）の式は，実用的な解析ではほとんど用 いられないが, e) 有限ひずみ・有限変位の式の解に収 束する最低次の非線形式であり ${ }^{1)}$, 理論上の重要性から 検討に加える.

剛体回転除去後の回転角評価式としては, 通常, 剛体 回転除去後の回転角が微小ということで, 線形の評価式 $\hat{v}_{0}^{\prime}=\hat{\alpha}$ が用いられることが多いが，より回転角を敛密に 評価するという目的のもとに, 高次非線形の評価式 $\hat{v}_{0}^{\prime}=\sin \hat{\alpha}, \hat{v}_{0}^{\prime}=\tan \hat{\alpha}$ も用いられることがある. 局所 座標系 Iについては, すでに, 最も単純な線形の評価式 の精度がよく，高次非線形の評価式を用いても精度は向 上せず，逆に低下する可能性もあることが判明してい る ${ }^{1)}$. 局所座標系 II のもとでも，同様の結果が類推され るが，理論的に近似の程度を明示するためにここでは
Table 1 Expressions with Separation of Rigid Body Displacements.

\begin{tabular}{|c|c|c|c|c|}
\hline \multirow{2}{*}{ Theories } & \multirow{2}{*}{$\begin{array}{l}\text { Equilibrium } \\
\text { Equations }\end{array}$} & \multicolumn{2}{|c|}{ Boundary Conditions } & \multirow{2}{*}{$\begin{array}{l}\text { Stress Resultants } \\
\text { vs. Displacements }\end{array}$} \\
\hline & & Mechanical & Geometrical & \\
\hline $\begin{array}{l}\text { a) Small } \\
\text { Displacements }\end{array}$ & $\begin{array}{l}M^{\prime \prime}=0 \\
N^{\prime}=0\end{array}$ & $\begin{array}{l}M^{\prime}=\overline{\hat{F}}_{y} \\
N=\overline{\hat{F}}_{\mathbf{Z}} \\
M=\bar{M}\end{array}$ & $\begin{array}{l}\hat{v}_{0}=\overline{\hat{v}}_{0} \\
\hat{\omega}_{0}=\overline{\hat{\omega}}_{0} \\
\hat{v}_{0}^{\prime}=\overline{\hat{\alpha}}\end{array}$ & $\begin{array}{l}M=-E I \hat{v}_{o}^{\prime \prime} \\
N=E A \hat{\omega}_{o}^{\prime}\end{array}$ \\
\hline b) Beam-Colurin & $\begin{array}{l}\left(N \hat{v}_{0}^{\prime}+M^{\prime}\right)^{\prime}=0 \\
N^{\prime}=0\end{array}$ & $\begin{array}{l}N \hat{v}_{0}^{\prime}+M^{\prime}=\overline{\hat{F}}_{y} \\
N=\bar{F}_{\mathbf{z}} \\
M=\bar{M}\end{array}$ & $\begin{array}{l}\hat{v}_{0}=\overline{\hat{v}}_{0} \\
\hat{w}_{0}=\overline{\hat{\omega}}_{0} \\
\hat{v}_{0}^{\prime}=\overline{\hat{\alpha}}\end{array}$ & $\begin{array}{l}M=-E I \hat{v}_{o}^{\prime \prime} \\
N=E A\left(\hat{w}_{o}^{\prime}+\frac{1}{2} \hat{v}_{o}^{\prime 2}\right)\end{array}$ \\
\hline $\begin{array}{l}\text { c) Linearized } \\
\text { Beam-Column }\end{array}$ & $\begin{array}{l}\left(N \hat{v}_{o}^{\prime}+M^{\prime}\right)^{\prime}=0 \\
N^{\prime}=0\end{array}$ & $\begin{array}{l}N \hat{v}_{o}^{\prime}+M^{\prime}=\overline{\hat{F}}_{y} \\
N=\bar{F}_{\mathbf{z}} \\
M=\bar{M}\end{array}$ & $\begin{array}{l}\hat{v}_{0}=\overline{\hat{v}}_{0} \\
\hat{\omega}_{o}=\overline{\hat{\omega}}_{0} \\
\hat{v}_{o}^{\prime}=\overline{\hat{\alpha}}^{-\alpha}\end{array}$ & $\begin{array}{l}M=-E I \hat{v}_{o}^{\prime \prime} \\
N=E A \hat{\omega}_{o}^{\prime}\end{array}$ \\
\hline $\begin{array}{l}\text { d) Theor } \frac{1}{y} \text { ) convergent to } \\
\text { Finite Displacements } \\
\text { with Finite Strains }\end{array}$ & $\begin{array}{l}\left(\frac{M^{\prime}}{I+\hat{\omega}_{o}^{\prime}}\right)^{\prime}=0 \\
N^{\prime}=0\end{array}$ & $\begin{array}{l}\frac{M^{\prime}}{1+\hat{\omega}_{o}^{\prime}}=\overline{\hat{F}}_{y} \\
N=\bar{F}_{\mathbf{z}} \\
M=\bar{M}\end{array}$ & $\begin{array}{l}\hat{v}_{0}=\overline{\hat{v}}_{0} \\
\hat{\omega}_{o}=\overline{\hat{\omega}}_{0} \\
\hat{v}_{0}^{\prime}=\overline{\hat{\alpha}}\end{array}$ & $\begin{array}{l}M=-E I \hat{v}_{0}^{\prime \prime} \\
N=E A \hat{\omega}_{0}^{\prime}\end{array}$ \\
\hline
\end{tabular}

Remarks:The following notations are used throughout Tables presented as $E=$ Young's Modulus, $A=$ Cross Sectional Area, $I=$ Second Moment of Inertia, $\mathrm{N}=\mathrm{Axial}$ Stress Resultants, and $\left(\overline{\hat{F}}_{y}, \overline{\hat{F}}_{z}, \bar{M}\right)$ and $\left(\overline{\hat{v}}_{0}, \overline{\hat{w}}_{0}, \overline{\hat{\alpha}}_{)}\right)$Prescribed Boundary Values expressed in terms of the local components
Table 2 Evaluation of Rotational Angle after Separation of Rigid Body Rotation.

\begin{tabular}{|l|l|}
\hline & Eq. for Evaluation \\
\hline 1) & $\hat{v}_{o}^{\prime}=\hat{\alpha}$ \\
\hline 2) & $\hat{v}_{o}^{\prime}=\sin \hat{\alpha}$ \\
\hline 3) & $\hat{v}_{o}^{\prime}=\tan \hat{\alpha}$ \\
\hline
\end{tabular}


Table 3 Direct Lagrangian Expressions.

\begin{tabular}{|c|c|c|c|c|}
\hline \multirow{2}{*}{ Theories } & \multirow{2}{*}{$\begin{array}{l}\text { Equilibrium } \\
\text { Equations }\end{array}$} & \multicolumn{2}{|c|}{ Boundary Conditions } & \multirow{2}{*}{$\begin{array}{l}\text { Stress Resultants } \\
\text { vs. Displacements }\end{array}$} \\
\hline & & Mechanical & Geometrical & \\
\hline $\begin{array}{l}\text { e) Finite Displacements } \\
\text { with Finite Strains }\end{array}$ & $\begin{array}{l}\left\{N \sin \alpha+\frac{M^{\prime}}{\sqrt{g_{0}}} \cos \alpha\right\}^{\prime}=0 \\
\left\{N \cos \alpha-\frac{M^{\prime}}{\sqrt{g_{0}}} \sin \alpha\right\}^{\prime}=0\end{array}$ & $\begin{array}{l}N \sin \alpha+\frac{M^{\prime}}{\sqrt{g_{0}}} \cos \alpha=\bar{F}_{\mathrm{y}} \\
N \cos \alpha-\frac{M^{\prime}}{\sqrt{g_{0}}} \sin \alpha=\bar{F}_{\mathrm{z}} \\
M=\bar{M}\end{array}$ & $\begin{array}{l}v_{0}=\bar{v}_{0} \\
w_{0}=\bar{w}_{0} \\
\alpha=\bar{\alpha}\end{array}$ & $\begin{array}{l}N=E A\left(\sqrt{g_{0}}-1\right) \\
M=-E I \alpha^{\prime}\end{array}$ \\
\hline $\begin{array}{l}\text { f) Finite Displacements } \\
\text { with Small Strains }\end{array}$ & $\begin{array}{l}\left\{N \sin \alpha+M^{\prime} \cos \alpha\right\}^{\prime}=0 \\
\left\{N \cos \alpha-M^{\prime} \sin \alpha\right\}^{\prime}=0\end{array}$ & $\begin{array}{l}N \sin \alpha+M^{\prime} \cos \alpha=\bar{F}_{\mathrm{Y}} \\
N \cos \alpha-M^{\prime} \sin \alpha=\bar{F}_{\mathrm{z}} \\
M=\bar{M}\end{array}$ & $\begin{array}{l}v_{0}=\bar{v}_{0} \\
w_{0}=\bar{w}_{0} \\
\alpha=\bar{\alpha}\end{array}$ & $\begin{array}{l}N=E A\left(\sqrt{g_{0}}-1\right) \\
M=-E I \alpha^{\prime}\end{array}$ \\
\hline $\begin{array}{l}\text { g) Inextensional Finite } \\
\text { Displacements } \\
\text { (Inextensional Elastica) }\end{array}$ & $\begin{array}{l}\left\{N \sin \alpha+M^{\prime} \cos \alpha\right\}^{\prime}=0 \\
\left\{N \cos \alpha-M^{\prime} \sin \alpha\right\}^{\prime}=0\end{array}$ & $\begin{array}{l}N \sin \alpha+M^{\prime} \cos \alpha=\bar{F}_{\mathrm{Y}} \\
N \cos \alpha-M^{\prime} \sin \alpha=\bar{F}_{\mathbf{z}} \\
M=\bar{M}\end{array}$ & $\begin{array}{l}v_{0}=\bar{v}_{0} \\
v_{0}=\bar{\omega}_{0} \\
\alpha=\bar{\alpha}\end{array}$ & $\begin{array}{l}\sqrt{g_{0}}=1 \\
M=-E I \alpha^{\prime}\end{array}$ \\
\hline
\end{tabular}

Remarks: $\left(\bar{F}_{y}, \bar{F}_{\mathbf{z}}, \bar{M}\right)$ and $\left(\bar{v}_{0}, \bar{w}_{0}, \bar{\alpha}\right)=$ Prescribed Boundary Values

検討項目に加える.

\section{3. 検討手法の概要}

検討手法としては，文献 1)〜3）に準ずる.

まず Fig. 1 の有限要素 $i, i+1$ に関して, $i$ 節点の物 理量 $\left.Q_{J}\right|_{\imath}$ を $i+1$ 節点の物理量 $\left.Q_{j}\right|_{i+1}$ へ伝達する形式 の次のような離散化式を各種剛体変位除去の手法で求 め,これを要素長 $l$ に関する次のようなべき級数展開で 表現する.

$$
\left.Q_{J}\right|_{\imath+1}=\left.Q_{J}\right|_{\imath}+\left.\sum_{n=1}^{\infty} Q_{J}^{(n)}\right|_{\imath}\left(l^{n} / n !\right)
$$

ここに, ベき級数係数 $Q_{J}^{(n)} \mid$ 、は $i$ 節点における物理量 $Q, の n$ 階の微係数で, $i$ 節点における物理量 $\left.Q_{m}\right|_{\text {。 }}$ $(m=1 \sim 6)$ で表わされる.

次に，䈌密解とみなし比較基準となる Table 3 の Lagrange 表現の高次非線形の支配方程式加ら Taylor 展開法により, 式 (1) と同じ表現の離散化式を導く. そして, 㣚体変位除去の手法の精度は, 式 (1) のべき 級数係数に関して, 䍑体変位除去の手法によるものが, Lagrange 表現の高次非線形の支配方程式によるもの と，いかに高次項まで一致するかによって評価される. なお，この精度評価手法の妥当性は，文献 4 ）により数 値的にも検証されている。

精度評価に，式（1）に示すような，要素長に関する べき級数展開式を用いる主たる理由としては, 要素分割 長を小さくしていった場合の解の収束性, ならびに精度 を要素長のオーダーで評価するためであるが，もう1つ の理由として, Lagrange 表現の高次非線形の支配方程 式から式（1）の形が比較的容易に導けることにもよる.

剛体変位の除去において，局所座標系 I を用いる場合 は1), 局所系での幾何学的境界条件がすべて $i$ 節点で与 えられているので, 式（1）に示す伝達形の離散化式の
誘導は微分方程式の初期値問題を解くことに帰着され る.したがって, Lagrange 表現の高次非線形微分方程 式と同様, 局所系の低次非線形支配方程式の解法に Taylor 展開法を用いれば，伝達形の離散化式を求める のは容易である. 一方，局所座標系 II を用いる場合につ いては, 局所系の変位拘束条件が $i$ 節点のほかに $i+1$ 節点についても与えられるので, 局所系の離散化式の誘 導は, 微分方程式の境界值問題を解くことに帰着される. このため, 非線形の局所系の式である b) はり・柱の式, c）線形化はり・柱の式に関しては, 一般的な伝達形の 離散化式を誘導するのが困難となり，また他の局所系の 式を用いる場合においても，その誘導は繁雑である。こ れが, 文献 1 ) 3）で局所座標系 Iについてのみ扱った 主たる理由である。

しかしながら， Table1に示すように，局所系の支配 微分方程式で分布荷重項をすべて無視すれば，局所座標 系 II の場合でも，解析的に境界値問題が解け，非常に繁 雑ではあるが, 式 $(1$ ) の形の伝達形の離散化式の誘導 が可能になる. また, 分布荷重項は, 通常の解析でも, 集中荷重に置換されることが多く，これを無視すること で,それほど一般性を欠くことになるとは考えられない。

以上から，次節では，分布荷重を無視することで，局 所座標系 II を用いた場合の離散化式を求める.なお, Lagrange 表現の高次非線形支配微分方程式から，伝達 形の離散化式の誘導過程はすでに文献 1 ) に述べている ので，ここでは説明を省略する.

\section{4. 剛体变位除去の手法による伝達形離散化式 の誘道}

\section{（1）局所座標系 II と全体座槚系の物理且の関係}

式（1）に示す離散化式を全体座標系の物理成分で表 わす都合上，局所座標系の成分と全体座標系の成分の関 
係を求めておく必要がある。この関係は，はり要素の剛 体運動に関する簡単な幾何学的考察によって求めること ができる.

まず，幾何学量について考える．剛体変位を除去した 局所座標系 II $(\hat{y}, \hat{z})$ では, 要素節点での並進変位成 分 $\left(\left.\hat{v}_{0}\right|_{k},\left.\hat{w}_{0}\right|_{k}\right)(k=i, i+1)$ について, 次の拘束条件 が与えられる.

$$
\left.\hat{v}_{0}\right|_{t}=\left.\hat{w}_{0}\right|_{t} \equiv 0,\left.\quad \hat{v}_{0}\right|_{t+1} \equiv 0
$$

上記の拘束条件と Fig. 2 (a) の幾何学的関係を考虑 すると, 局所系での並進変位成分 $\left.\hat{w}_{0}\right|_{t+1}$, 回転成分 $\hat{\alpha}_{k}$ と全体座標系 $(y, z)$ における並進変位成分 $\left(\left.v_{0}\right|_{k}\right.$, $\left.\left.w_{0}\right|_{k} ^{\prime}\right)$, 回転成分 $\alpha_{k}$ の関係は次のようになる。

$$
\begin{aligned}
\left\{\begin{array}{c}
\left.v_{0}\right|_{i+1}-\left.v_{0}\right|_{i} \\
\left.w_{0}\right|_{i+1}-\left.w_{0}\right|_{i}+l \\
\alpha_{i+1}-\alpha_{i}
\end{array}\right\}= & {\left[\begin{array}{c}
\cos \left(\alpha_{i}-\hat{\alpha}_{i}\right), \sin \left(\alpha_{i}-\hat{\alpha}_{i}\right), 0 \\
-\sin \left(\alpha_{i}-\hat{\alpha}_{i}\right), \cos \left(\alpha_{i}-\hat{\alpha}_{i}\right), 0 \\
0 \quad, \quad 0 \quad, 1
\end{array}\right] } \\
& \cdot\left\{\begin{array}{c}
0 \\
\left.\hat{w}_{0}\right|_{i+1}+l \\
\hat{\alpha}_{i+1}-\hat{\alpha}_{i}
\end{array}\right\} \cdots \cdots \cdots \cdots \cdots(3)
\end{aligned}
$$

また，力学量についても, Fig.2 (b) より節点力の 局所座標系の成分 $\left(\hat{F}_{z k}, \hat{F}_{y k}, M_{k}\right)(k=i, i+1)$ と全 体座標系の成分 $\left(F_{z k}, F_{y k}, M_{k}\right)$ さらに，節点における 断面力成分 $\left(N_{k}, V_{k}, M_{k}\right)$ の関係として次式を得る.

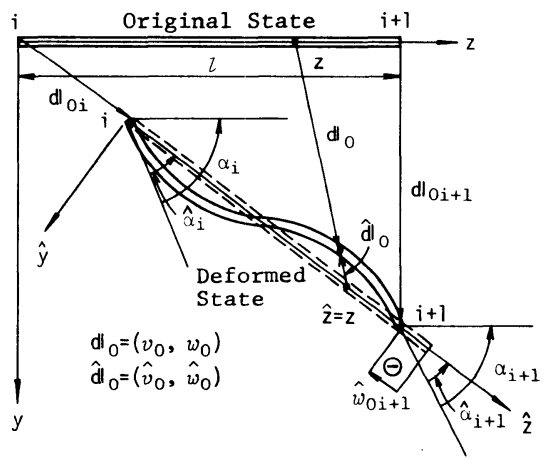

(a) Geometrical Relation

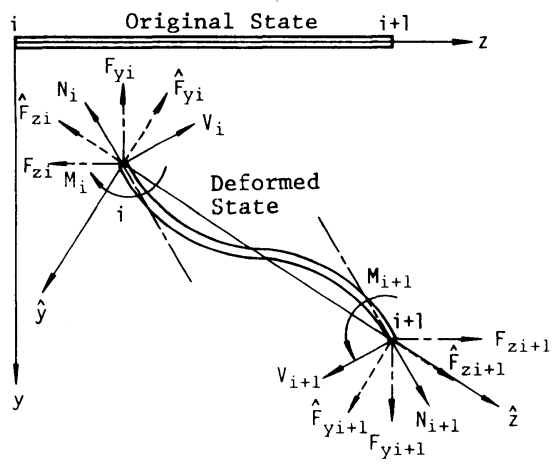

(b) Mechanical Relation

Fig. 2 Components of Physical Quantities.

$$
\left\{\begin{array}{l}
F_{y k} \\
F_{z k} \\
M_{k}
\end{array}\right\}=\left[\begin{array}{cc}
\cos \left(\alpha_{k}-\hat{\alpha}_{k}\right), \sin \left(\alpha_{k}-\hat{\alpha}_{k}\right), 0 \\
-\sin \left(\alpha_{k}-\hat{\alpha}_{k}\right), \cos \left(\alpha_{k}-\hat{\alpha}_{k}\right), 0 \\
0 \quad, \quad 0 \quad, 1
\end{array}\right]\left\{\begin{array}{c}
\hat{F}_{y k} \\
\hat{F}_{z k} \\
M_{k}
\end{array}\right\}
$$

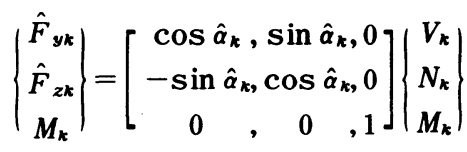

ここで, 注意しなければならないのは, 式（5）に示 すように，䍑体回転除去後の局所系においても， Table 1 に示すすべての支配方程式を通じ，局所座標系 $(\hat{y}, \hat{z})$ 方向の節点力成分と断面力成分を区別していることであ る6). すなわち, Table 1 の力学的境界条件のところで 与えられる力の成分 $\hat{F}_{z k}, \hat{F}_{y k}$ は断面力成分ではなく, 断面力成分は式（5)によって評価しなければならない. なお, 明らかなように, $i, i+1$ 要素に分布荷重が作用 しない本論文の場合は, $\left(\hat{F}_{z i}, \hat{F}_{y i}\right)$ と $\left(\hat{F}_{z i+1}, \hat{F}_{y i+1}\right)$ とは等しくなる.

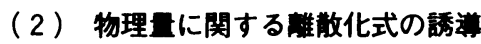

収束性, 精度を検証する物理量としては, 設計におい て，重要であるものということで，次のような全体座標 系における並進, 回転ならびに断面力, 断面モーメント 成分を選び，これらに関して式（1）の形の離散化式を 誘導する。

$\{Q\}=\left\{v_{0}, w_{0}, \alpha, V, N, M\right\}$

ここでは，文献 1)，2）で用いた節点力の全体座標系 の成分 $\left(F_{z}, F_{y}\right)$ に代えて, 断面力成分 $(N, V)$ を力 の成分として採用しているが, これは, 式 (4), (5) を用いれば断面力成分についても収束解が得られるこ と6)を明示するためである.

局所座標系 II では, 式 (3)〜（5）を用いて，式（6） の物理量で表わされた式 (1) の形の離散化式を誘道す るが,このためには，まず式（3)〜（5) に含まれる局 所系での物理量成分 $\hat{\alpha}_{l}, \hat{\alpha}_{i+1},\left.\hat{w}_{0}\right|_{t+1}, M_{i+1}$ を Table 1 に 示す局所系の支配方程式を用いて算定する必要がある. $\hat{\alpha}_{\iota}$ の算定は，3. で述べたように，式（2）に示す拘束 条件のもとに，微分方程式を境界値問題として解くこと に帰着される．このようにして，唋に対応する $\left.\hat{v}_{0}^{\prime}\right|_{\imath}$ を 局所系の各種支配方程式加求めた結果を，Table 4 に とりまとめる.

$\hat{\alpha}_{\imath}$ は $\left.\hat{v}_{0}^{\prime}\right|_{\imath}$ をもとに, Table 2 の回転角評価式により， おのおの算定することができる. $\hat{\alpha}_{i+1},\left.\hat{w}_{0}\right|_{t+1}, M_{i+1}$ につ

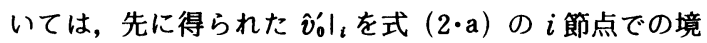
界条件に含め, 微分方程式を初期値問題として解くこと で算定される.

物理量 $\left(v_{0}, w_{0}, \alpha, M\right)$ に関する式（1）の形式の離 散化式は, 以上のようにして求めた局所系の物理量 
$\left(\hat{\alpha}_{i}, \hat{\alpha}_{i+1},\left.\hat{w}_{0}\right|_{i+1}, M_{i+1}\right)$ を式 $(3) \sim(5)$ に代入し, さらに,これらの中に含まれる $\sin \hat{\alpha}_{i}, \cos \hat{\alpha}_{i}, \sin \gamma l$, $\cos \gamma l, \sinh \gamma l, \cosh \gamma l$ を要素長 $l$ に関してべき級数 展開し，整理することで求めることができる．また，断 面力 $(N, V)$ に関する離散化式は, 式 $(5)$ に $i, i+1$ 節点での節点力の $(\hat{y}, \hat{z})$ 成分が同一であることを考 慮して得られる式

$$
\left\{\begin{array}{c}
V_{i+1} \\
N_{i+1}
\end{array}\right\}=\left[\begin{array}{c}
\cos \hat{\alpha}_{i+1},-\sin \hat{\alpha}_{i+1} \\
\sin \hat{\alpha}_{i+1}, \cos \hat{\alpha}_{i+1}
\end{array}\right]\left\{\begin{array}{c}
\hat{F}_{y t} \\
\hat{F}_{z i}
\end{array}\right\} \cdots
$$

に， $\hat{\alpha}_{l+1}$ を代入し，lについてべき級数展開することで 求められる.

このとき, 式 $(7)$ の右辺において,$i$ 節点での節点 力成分 $\hat{F}_{z i}, \hat{F}_{y i}$ に代え，式（6）の断面力成分 $N_{i}, V_{i}$ を用いるには, 式（5）により，前者を後者に変換する 必要がある. しかしながら, 式 $(5)$ の座標変換行列に 含まれる $\hat{\alpha}_{i}$ は Table 4 からわかるように $\hat{F}_{z l}, \hat{F}_{y i}$ の関
数となり,ただちに $\hat{F}_{z i}, \hat{F}_{y i}$ を $N_{i}, V_{i}$ に変換できない. したがって，ここでは補遗のごとく, $\hat{F}_{z i}, \hat{F}_{y i}$ を $l$ に ついてべき級数展開し, 低次項から高次項へ逐次変換す る手法をとった。

このようにして, Table 1 に示す局所系の支配方程式 と Table 2 の回転角評価式の各種組合せについて式 (1) に示す離散化式のべき級数係数に対応する微係数 $\left.Q_{J}^{(n)}\right|_{\text {i }}$ を求めた。

結果は, 棒材の軸線の伸張変形を考慮する場合とこれ を無視する場合とに分け，Table 5，6にまとめた。こ こでは, 近似の程度が明確になるように, 㣚体変位除去 の手法で得られた各物理量に関する微係数を, 厳密なも のと考えられる Table 3 に示す Lagrange 表現の高次非 線形微分方程式によるものと，低次から高次へと，一致 する所まで此較する形で示している．ただし，Table 5, 6 では頁数の制限から, 具体的に示した微係数としては,

Table $4 \hat{v}_{0}^{\prime} l_{\imath}$ expressed in terms of Mechanical Components.

\begin{tabular}{|c|c|c|}
\hline a) & Small Displacements & $\left.\hat{v}_{0}^{\prime}\right|_{i}=\frac{M_{j} l}{2 E I}+\frac{\hat{F}_{4 i}}{6 E I} l^{2}$ \\
\hline b) & Beam-Col umn & $\hat{F}_{z i \geq 0} \quad \gamma^{2}=\left|\hat{F}_{z i}\right| / E I$ \\
\hline c) & Linearized & $\begin{array}{l}\left.\hat{v}_{0}^{\prime}\right|_{i}=\frac{M_{i} l}{E I} \frac{1}{\gamma l}\left(\frac{\cosh \gamma l-1}{\sinh \gamma l}\right)+\frac{\hat{F}_{y i} l^{2}}{E I} \frac{1}{(\gamma l)^{2}}\left(\frac{\sinh \gamma l-\gamma l}{\sinh \gamma l}\right) \\
\hat{F}_{z i}<0 \quad \gamma^{2}=\left|\hat{F}_{z i}\right| / E I\end{array}$ \\
\hline & & $\left.\hat{v}_{0}^{\prime}\right|_{i}=\frac{M_{i} l}{E I} \frac{1}{\gamma l}\left(\frac{1-\cos \gamma l}{\sin \gamma l}\right)-\frac{\hat{F}_{y i} l^{2}}{E I} \frac{1}{(\gamma l)^{2}}\left(\frac{\sin \gamma l-\gamma l}{\sin \gamma l}\right)$ \\
\hline d) & $\begin{array}{l}\text { Theory } 11 \text { convergent } \\
\text { to FD with FS }\end{array}$ & $\left.\hat{v}_{0}^{\prime}\right|_{i}=\frac{M_{i} l}{2 E I}+\frac{\hat{F}_{y i}}{6 E I}\left(1+\frac{\hat{F}_{z i}}{E A}\right) l^{2}$ \\
\hline
\end{tabular}

Remarks: FD with FS = Finite Displacements with Finite Strains

Table 5 Derivatives of Physical Quantities.

(a) Derivatives of $v_{0}$

\begin{tabular}{|c|c|c|c|c|c|}
\hline \multicolumn{3}{|r|}{ The ories } & $\left.v_{0}^{\prime}\right|_{i}$ & $\left.v_{0}^{\prime \prime}\right|_{i}$ & $\left.v_{0}{ }^{\prime \prime \prime}\right|_{i}$ \\
\hline \multirow{2}{*}{ 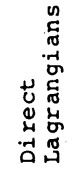 } & \multicolumn{2}{|r|}{$\begin{array}{l}\text { Finite Displacements } \\
\text { with Finite Strains }\end{array}$} & \multirow{6}{*}{$\lambda s$} & \multirow{6}{*}{$-\lambda K c-V_{i} K s / a$} & $-\lambda^{2} V_{i} c / b-\lambda k^{2} s+2 V_{i} k^{2} c / a-N_{i} k^{2} s / a-\lambda V_{i}^{2} s / a b$ \\
\hline & f) & $\begin{array}{l}\text { Finite Displacements } \\
\text { with Small Strains }\end{array}$ & & & $-\lambda V_{i} c / b-\lambda k^{2} s+2 V_{i} \kappa^{2} c / a-N_{i} \kappa^{2} s / a-V_{i}^{2} s / a b$ \\
\hline \multirow{4}{*}{ 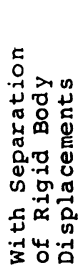 } & \multirow{4}{*}{ 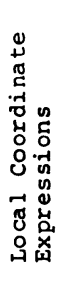 } & $\begin{array}{l}\text { a) Small } \\
\text { Displacements }\end{array}$ & & & $-\lambda V_{i} c / b-\frac{3}{4} \lambda \kappa^{2} s+\frac{3}{2} V_{i} \kappa^{2} c / a-\frac{3}{4} N_{i} k^{2} s / a-V_{j}^{2} s / a b$ \\
\hline & & b) Beam-Column & & & $-\lambda V_{i} c / b-\lambda k^{2} s+\frac{3}{2} V_{i} k^{2} c / a-\frac{1}{2} N_{i} k^{2} s / a-V_{i}^{2} s / a b$ \\
\hline & & $\begin{array}{l}\text { c) Linearized } \\
\text { Beam-Column }\end{array}$ & & & $-\lambda V_{i} c / b-\frac{3}{4} \lambda \kappa^{2} s+\frac{3}{2} V_{i} \kappa^{2} c / a-\frac{3}{4} N_{i} \kappa^{2} s / a-V_{i}^{2} s / a b$ \\
\hline & & $\begin{array}{l}\text { d) Theory l) convergent } \\
\text { to FD with FS }\end{array}$ & & & $-\lambda^{2} V_{i} c / b-\frac{3}{4} \lambda \kappa^{2} s+\frac{3}{2} V_{i} k^{2} c / a-\frac{3}{4} N_{i} k^{2} s / a-\lambda V_{i}^{2} s / a b$ \\
\hline
\end{tabular}

Remarks: The following notations are used throughout Tables 5,6 $K=M_{i} / E I, \lambda=\sqrt{g_{0}}=N_{i} / E A+1, \quad s=\sin \alpha, c=\cos \alpha, E A=a, E I=b$ FD with $\mathrm{FS}=$ Finite Displacements with Finite Strains 
Table 5 Continued

(b) Derivatives of $\alpha$

\begin{tabular}{|c|c|c|c|c|c|c|c|}
\hline \multicolumn{5}{|c|}{ Theories } & $\left.\alpha^{\prime}\right|_{i}$ & $\left.\because "\right|_{i}$ & $\left.\alpha^{\prime \prime \prime \prime}\right|_{i}$ \\
\hline \multirow{2}{*}{ 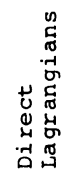 } & \multicolumn{2}{|c|}{ e) } & \multicolumn{2}{|c|}{$\begin{array}{l}\text { Finite Displacements } \\
\text { with Finite Strains }\end{array}$} & \multirow{11}{*}{$-k$} & $-\lambda V_{i^{\prime}}^{\prime / 2}$ & $-\lambda N_{i} k / b+V_{i}^{2} k / a b$ \\
\hline & \multicolumn{2}{|c|}{ f) } & \multicolumn{2}{|c|}{$\begin{array}{l}\text { Finite Displacements } \\
\text { with Small Strains }\end{array}$} & & \multirow{7}{*}{$-V_{i} / b$} & $-N_{i} \kappa / b$ \\
\hline \multirow{9}{*}{ 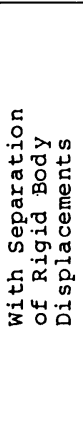 } & \multirow{9}{*}{ 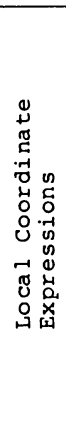 } & \multirow{3}{*}{\multicolumn{2}{|c|}{$\begin{array}{l}\text { a) Small } \\
\text { Displa cements }\end{array}$}} & $\hat{v}_{0}^{\prime}=\hat{\alpha}$ & & & $-\frac{3}{2} N_{i} k / b$ \\
\hline & & & & $\hat{v}_{0}^{\prime}=\sin \hat{\alpha}$ & & & $-\frac{3}{2} N_{i} k / b-\frac{1}{4} k^{3}$ \\
\hline & & & & $\hat{v}_{0}^{\prime}=\tan \hat{\alpha}$ & & & $-\frac{3}{2} N_{i} k / b+\frac{1}{2} k^{3}$ \\
\hline & & \multirow{3}{*}{$\begin{array}{l}\text { b) } \\
\text { c) }\end{array}$} & \multirow{3}{*}{$\begin{array}{l}\text { Beam-Col umn } \\
\text { Li nearized } \\
\text { Beam-Col umn }\end{array}$} & $\hat{v}_{0}^{\prime}=\hat{x}$ & & & $-N_{i} k / b$ \\
\hline & & & & $\hat{v}_{0}^{\prime}=\sin \hat{\alpha}$ & & & $-N_{i} k / b-\frac{1}{4} k^{3}$ \\
\hline & & & & $\hat{v}_{\dot{v}}=\tan \hat{\alpha}$ & & & $-N_{i} \kappa / b+\frac{1}{2} \kappa^{3}$ \\
\hline & & \multirow[t]{3}{*}{ d) } & \multirow{3}{*}{$\begin{array}{l}\text { Theory }{ }^{1)} \\
\text { convergent to } \\
\text { FD with FS }\end{array}$} & $\hat{v}_{0}^{\prime}=\hat{\alpha}$ & & \multirow{3}{*}{$-\lambda V_{i} / t$} & $-\frac{3}{2} \lambda N_{i} \kappa / b+\frac{3}{2} V_{i}^{2} \kappa / a b$ \\
\hline & & & & $\hat{v_{0}^{\prime}=\sin \hat{\alpha}}$ & & & $-\frac{3}{2} \lambda N_{i} \kappa / b+\frac{3}{2} V_{i}^{2} k / a b-\frac{1}{4} \kappa^{3}$ \\
\hline & & & & $\hat{v}_{0}^{\prime}=\tan \hat{\alpha}$ & & & $-\frac{3}{2} \lambda N_{i} k / b+\frac{3}{2} V_{i}^{2} k / a b+\frac{1}{2} k^{3}$ \\
\hline
\end{tabular}

(c) Derivatives of $\mathrm{N}$

\begin{tabular}{|c|c|c|c|c|c|c|c|}
\hline \multicolumn{5}{|c|}{ Theories } & $\left.N^{\prime}\right|_{i}$ & $\left.N^{\prime \prime}\right|_{i}$ & $\left.N^{\prime \prime \prime}\right|_{i}$ \\
\hline \multirow{2}{*}{ 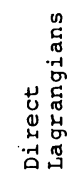 } & \multicolumn{2}{|r|}{ e) } & \multicolumn{2}{|c|}{$\begin{array}{l}\text { Finite Displacements } \\
\text { with Finite Strains }\end{array}$} & \multirow{11}{*}{$-V_{i}{ }^{k}$} & $-N_{i} k^{2}-\left.\lambda\right|_{i} ^{2} / b$ & $V_{i} k^{3}-4 \lambda V_{i} N_{i} k / b+V_{i}^{3} k / a b$ \\
\hline & \multicolumn{2}{|r|}{ f) } & \multicolumn{2}{|c|}{$\begin{array}{l}\text { Finite Displacements } \\
\text { with Small Strains }\end{array}$} & & \multirow{7}{*}{$-N_{i} \kappa^{2}-V_{i}^{2} / b$} & $V_{i} \kappa^{3}-4 V_{i} N_{i} \kappa / b$ \\
\hline \multirow{9}{*}{ 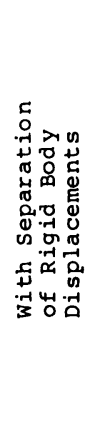 } & \multirow{9}{*}{ 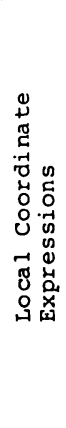 } & \multirow{3}{*}{\multicolumn{2}{|c|}{$\begin{array}{l}\text { a) Small } \\
\text { Displacements }\end{array}$}} & $\hat{v}_{0}^{\prime}=\hat{\alpha}$ & & & $V_{i} \kappa^{3}-\frac{9}{2} V_{i} N_{i} \kappa / b$ \\
\hline & & & & $\hat{v}_{0}^{\prime}=\sin \hat{\alpha}$ & & & $\frac{3}{4} V_{i} k^{3}-\frac{9}{2} V_{i} N_{i} \kappa / b$ \\
\hline & & & & $\hat{v}_{0}^{\prime}=\tan \hat{\alpha}$ & & & $\frac{3}{2} V_{i} k^{3}-\frac{9}{2} V_{i} N_{i} k / b$ \\
\hline & & \multirow{3}{*}{$\begin{array}{l}\text { b) } \\
\text { c) }\end{array}$} & \multirow{3}{*}{$\begin{array}{l}\text { Beam-Col umn } \\
\text { Li nearized } \\
\text { Beam-Column }\end{array}$} & $\hat{v}_{0}^{\prime}=\hat{\alpha}$ & & & $V_{i} \mathrm{~K}^{3}-4 V_{i} l_{i} \mathrm{k} / b$ \\
\hline & & & & $\hat{v}_{0}^{\prime}=\sin \hat{\alpha}$ & & & $\frac{3}{4} V_{i} \kappa^{3}-4 V_{i} N_{i} \kappa / b$ \\
\hline & & & & $\hat{v}_{i}^{\prime}=\tan \hat{\alpha}$ & & & $\frac{3}{2} V_{i} k^{3}-4 V_{i} N_{i} k / b$ \\
\hline & & & \multirow{3}{*}{$\begin{array}{l}\text { Theory } \\
\text { convergent to } \\
\text { FD with FS }\end{array}$} & $\hat{v}_{0}^{\prime}=\hat{\alpha}$ & & \multirow{3}{*}{$-N_{i} K^{2}-\lambda V_{i}^{2} / b$} & $V_{i} k^{3}-\frac{9}{2} \lambda V_{i} N_{i}</ b+\frac{3}{2} V_{i}^{3} k / a b$ \\
\hline & & & & $\hat{y}_{0}^{\prime}=\sin \hat{\alpha}$ & & & $\frac{3}{4} V_{i} k^{3}-\frac{9}{2} \lambda V_{i} N_{i} k / b+\frac{3}{2} V_{i}^{3} k / a b$ \\
\hline & & & & $\hat{v}_{0}^{\prime}=\tan \hat{\alpha}$ & & & $\frac{3}{2} V_{i} k^{3}-\frac{9}{2} \lambda V_{i} N_{i} k / b+\frac{3}{2} V_{i}^{3} k / a b$ \\
\hline
\end{tabular}

並進変位の一方の成分 $v_{0}$, 回転成分 $\alpha$, 軸力成分 $N$ と 曲げモーメント $M$ とである. 残りの並進変位成分 $w_{0}$ とせん断力成分 $V$ については, 一致性状がそれぞれ $v_{0}$ および $N$ と同様であるので表示を省略している. さら に, 軸線の伸張変形を無視した Table 6 の場合, 並進変 位成分 $v_{0}$ 以外の物理量については, 軸線の伸張を考慮 した Table 5 の結果と同一であるため, $v_{0}$ に関する微 係数のみを示している. またTable 5 (a), (d), Table 6 (a) では, 表示したオーダーまでの微係数が Table 2 の回転角評価式によらないので，これによる区分を省略 している.さらに, 軸線の伸張変形を無視すると Table 1のd) の式は, a) 微小変位の式と一致するので Table 6では表示を省略している.

\section{5. 考察}

\section{（1） 要亲分割長を無限小としたときの収束解}

要素分割長を無限小とした極限では局所座標系 II $\boldsymbol{z}$ 軸は変形後の棒材軸線の接線となり, 局所座標系 I と一 致する. したがって，局所座標系 II を用いた場合の剛体 変位除去の手法の要素分割長無限小での収束解は, 局所 座標系 I の結果 ${ }^{1} よ り$ 予想できるが, ここでは一応, 理 論的に確認しておく. 
Table 5 Continued

(d) Derivatives of $M$

\begin{tabular}{|c|c|c|c|c|c|}
\hline \multicolumn{3}{|r|}{ Theories } & $\left.M^{\prime}\right|_{i}$ & $\left.M^{\prime \prime}\right|_{i}$ & $\left.M^{\prime \prime \prime}\right|_{i}$ \\
\hline \multirow{2}{*}{ 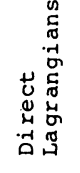 } & \multicolumn{2}{|r|}{$\begin{array}{l}\text { Finite Displacements } \\
\text { with Finite Strains }\end{array}$} & $\lambda v_{i}$ & $\lambda N_{i} k-V_{i}^{2} \kappa / a$ & $\lambda^{2} V_{i} N_{i} / b-\lambda V_{i} k^{2}-3 V_{i} N_{i} \kappa^{2} / a-\lambda V_{i}^{3} / a b$ \\
\hline & f) & $\begin{array}{l}\text { Finite Displacements } \\
\text { with Small Strains }\end{array}$ & \multirow{3}{*}{$V_{i}$} & \multirow{3}{*}{$N_{i} \mathrm{~K}$} & $V_{i} N_{i} / b-V_{i} \kappa^{2}$ \\
\hline \multirow{3}{*}{ 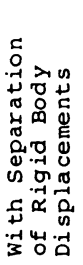 } & \multirow{3}{*}{ 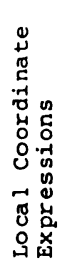 } & $\begin{array}{l}\text { a) Small } \\
\text { Displacements }\end{array}$ & & & \multirow[b]{2}{*}{$V_{i} N_{i} / b-\frac{3}{4} V_{i} k^{2}$} \\
\hline & & $\begin{array}{l}\text { b) Beam-Column } \\
\text { c) Li nearized } \\
\text { Beam-Column }\end{array}$ & & & \\
\hline & & $\begin{array}{l}\text { d) Theory l) convergent } \\
\text { to FD with FS }\end{array}$ & $\lambda V_{i}$ & $\lambda N_{i} k-V_{i}^{2} k / a$ & $\lambda^{2} V_{i} N_{i} / b-\frac{3}{4} \lambda V_{i} \kappa^{2}-\frac{9}{4} V_{i} N_{i} k^{2} / a-\lambda V_{i}^{3} / a b$ \\
\hline
\end{tabular}

Table 6 Derivatives of Physical Quantities with Inextensional Deformations.

(a) Derivatives of $v_{0}$

\begin{tabular}{|c|c|c|c|c|c|c|}
\hline \multicolumn{4}{|c|}{ Theories } & $\left.v_{0}^{\prime}\right|_{i}$ & $\left.v_{0}^{\prime \prime}\right|_{i}$ & $\left.v_{0}^{\prime \prime \prime}\right|_{i}$ \\
\hline 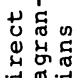 & g) & \multicolumn{2}{|c|}{$\begin{array}{l}\text { Inextensional } \\
\text { Finite Displacements }\end{array}$} & \multirow{4}{*}{$s$} & \multirow{4}{*}{$-K c$} & $-V_{i} c / b-k^{2} s$ \\
\hline \multirow{3}{*}{ 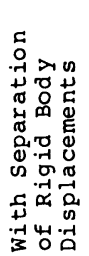 } & \multirow{3}{*}{ 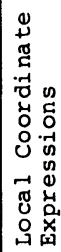 } & & $\begin{array}{l}\text { Small } \\
\text { Displacements }\end{array}$ & & & $-V_{i} c / b-\frac{3}{4} k^{2} s$ \\
\hline & & b) & Beam-Col umn & & & $-V_{i} c / b-\kappa^{2} s$ \\
\hline & & c) & $\begin{array}{l}\text { Li nearized } \\
\text { Beam-Column }\end{array}$ & & & $-V_{i} c / b-\frac{3}{4} k^{2} s$ \\
\hline
\end{tabular}

(a') Fourth Order Derivatives of $v_{0}$

\begin{tabular}{|l|l|l|}
\hline \multicolumn{2}{|c|}{ Theories } & \multicolumn{1}{c|}{$\left.v_{0}{ }^{(4)}\right|_{i}$} \\
\hline g) $\begin{array}{l}\text { Inextensiona 1 } \\
\text { Finite Displ acements }\end{array}$ & $-N_{i} \kappa c / b-3 V_{i} \kappa s / b+K^{3} c$ \\
\hline \multirow{3}{*}{ b) Beam-Column } & $\hat{v}_{0}^{\prime}=\hat{\alpha}$ & $-N_{i} \kappa c / b-3 V_{i} \kappa s / b+K^{3} c$ \\
\cline { 2 - 3 } & $\hat{v}_{0}^{\prime}=\sin \hat{\alpha}$ & $-N_{i} \kappa c / b-3 V_{i} \kappa s / b+\frac{1}{2} \kappa^{3} c$ \\
\cline { 2 - 3 } & $\hat{v}_{0}^{\prime}=\tan \hat{\alpha}$ & $-N_{i} \kappa c / b-3 V_{i} \kappa s / b+2 \kappa^{3} c$ \\
\hline
\end{tabular}

㓮体変位除去の手法の収束解の性質を知るには, 文献 1 ）に示すように，式（1）に示す離散化式の 1 次のべ き級数係数 $\left.Q_{j}^{(1)}\right|_{\text {。 }}$ 関して，Lagrange 表現の高次非線 形支配微分方程式から得られるものとの一致性状を調べ ればよい. Table 5，6から明らかなように，軸線の伸 張変形を考虑する場合, Table 2 の角度評価式の差によ らず, 局所系の支配方程式として, a) 微小変位の式, b) はり・柱の式，c) 線形化はり・柱の式を用いるときは, 討議(6)で問題となった断面力を含め, 物理量の 1 次のべ
き級数係数について,すべて, Table 3 の f) 微小ひずみ・ 有限変位の式によるものと一致する. したがって, a)〜 c）の局所系の式を用いた場合は, いずれも，f）微小ひ ずみ・有限変位の式の解に収束する. また，局所系の式 d) の場合は, 同様の検討により，e）有限ひずみ・有 限変位の式の解に収束することがわかる.さらに軸線の 伸張変形を無視する場合は, Table 1 のどの局所系の式 を用いても，g）軸線不伸張の有限変位の式の解に収束 する.

以上, 最初の予想どおり，局所座標系 II を用いた場合 の収束解に関する結果は, すべて, 局所座標系 I に関す る結果と一致することが確認された。

\section{（2）要来分割長が有限の場合の精度に関する検討}

要素分割長が有限の場合, 㣚体変位除去の手法の収束 解に対する精度は，本手法によって得られる式（1）の 1 次以上のべき級数係数が，（1）で示した収束解に対 して, いかに一致しているかを検討することで知ること 
Table 7 Coincidence of the Order of Derivatives.

\begin{tabular}{|c|c|c|c|c|c|c|c|c|}
\hline & $\begin{array}{r}\text { Convergent } \\
\text { Solutions } \\
\end{array}$ & & $\begin{array}{l}\text { ories used for } \\
\text { al Coordinates }\end{array}$ & $\begin{array}{c}\text { Evaluation of Small } \\
\text { Rotational Angles }\end{array}$ & $V, N$ & $M$ & $v_{0}, w_{0}$ & $\alpha$ \\
\hline \multirow{3}{*}{ f) } & \multirow{3}{*}{$\begin{array}{l}\text { Finite } \\
\text { Displacements } \\
\text { with } \\
\text { Small Strains }\end{array}$} & & $\begin{array}{l}\text { Small } \\
\text { Displacements }\end{array}$ & $\begin{array}{c}\hat{v}_{0}^{\prime}=\hat{\alpha} \\
\hat{v}_{0}^{\prime}=\sin \hat{\alpha} \\
\hat{v}_{0}^{\prime}=\tan \hat{\alpha}\end{array}$ & $2(2)$ & $2(1)$ & $2(1)$ & $2(2)$ \\
\hline & & & Beam Column & $\begin{array}{c}-\frac{\hat{v}_{0}^{\prime}=\hat{\alpha}}{\hat{\partial}_{0}^{\prime}=\sin \hat{\alpha}}--- \\
----1-1 \\
\hat{v}_{0}^{\prime}=\tan \hat{\alpha}\end{array}$ & $\begin{array}{r}3(3) \\
2(2)\end{array}$ & $2(2)$ & $2(1)$ & $\begin{array}{l}3(3) \\
2(2)\end{array}$ \\
\hline & & & $\begin{array}{l}\text { Linearized } \\
\text { Beam Column }\end{array}$ & $\begin{array}{c}\hat{v}_{0}^{\prime}=\hat{\alpha} \\
\hat{v}_{0}^{\prime}=\sin \hat{\alpha} \\
\hat{v}_{0}^{\prime}=\tan \hat{\alpha}\end{array}$ & $\begin{array}{r}3(3) \\
---1 \\
2(2)\end{array}$ & $2(2)$ & $2(1)$ & $\begin{array}{l}3(3) \\
--- \\
2(2)\end{array}$ \\
\hline e) & $\begin{array}{l}\text { Finite } \\
\text { Displacements } \\
\text { with } \\
\text { Finite } \\
\text { Strains }\end{array}$ & & $\begin{array}{l}\text { Theory }{ }^{11} \\
\text { convergent to } \\
\text { FD with FS }\end{array}$ & $\begin{array}{c}\hat{v}_{0}^{\prime}=\hat{\alpha} \\
\hat{v}_{0}^{\prime}=\sin \hat{\alpha} \\
-\frac{1}{v_{0}^{\prime}=\tan \hat{\alpha}}-- \\
-\end{array}$ & $2(2)$ & $2(1)$ & $2(1)$ & $2(2)$ \\
\hline \multirow{3}{*}{ g) } & \multirow{3}{*}{$\begin{array}{l}\text { Inextensional } \\
\text { Finite } \\
\text { Displacements }\end{array}$} & a) & $\begin{array}{l}\text { Small } \\
\text { Displacements }\end{array}$ & $\begin{array}{c}\hat{v}_{0}^{\prime}=\hat{\alpha} \\
\hat{v}_{u}^{\prime}=\sin \hat{\alpha} \\
\hat{v}_{0}^{\prime}=\tan \hat{\alpha}\end{array}$ & $2(2)$ & $2(1)$ & $2(2)$ & $2(2)$ \\
\hline & & & Beam Column & $\begin{array}{c}\hat{v}_{0}^{\prime}=\hat{\alpha} \\
\hat{v}_{0}^{\prime}=\sin \hat{\alpha} \\
\hat{v}_{0}^{\prime}=\tan \hat{\alpha}\end{array}---$ & $\begin{array}{c}3(3) \\
--- \\
2(2)\end{array}$ & $2(2)$ & $\begin{array}{l}4(3) \\
--- \\
3(3)\end{array}$ & $\begin{array}{l}3(3) \\
2(2)\end{array}$ \\
\hline & & & $\begin{array}{l}\text { Linearized } \\
\text { Beam Column }\end{array}$ & $\begin{array}{c}\hat{v}_{0}^{\prime}=\hat{\alpha} \\
-\frac{v_{0}^{\prime}=\sin \hat{\alpha}}{0}- \\
\hat{v}_{0}^{\prime}=\tan \hat{\alpha}\end{array}$ & $\begin{array}{r}3(3) \\
--- \\
2(2)\end{array}$ & $2(2)$ & $2(2)$ & $\begin{array}{r}3(3) \\
--- \\
2(2)\end{array}$ \\
\hline
\end{tabular}

( ): with Adoption of Local Coordinate I

Remarks: FD with FS = Finite Displacements with Finite Strains

ができる.

Table 5, 6 の結果をもとに, 各物理量について, 収 束解と一致する最高次のべき級数係数をf) 微小ひず み・有限変位の式, e) 有限ひずみ・有限変位の式, な らびに g）軸線不伸張の有限変位の式のそれぞれの解に 収束するグループに分け Table 7 に示す.さらに, 局所 座標系の違いによる精度の差を検討するために, 文献 1 ) により得られた局所座標系 Iを用いたときの結果を Table 7 の括弧内に記入している.

Table 7 を用い, 局所座標系の影響を中心に, 局所系 の支配方程式，および，剛体回転除去後の回転角評価式 が㣚体変位除去の手法の精度に及ぼす影響について考察 する.

まず，局所座標系の差による影響を検討する. Table 7 からわかるように局所座標系 II を用いた場合，局所座 標系 I に比へ，刚体変位除去の手法による各物理量のべ き級数係数の収束解に対する一致性状は, 全般的によく, いずれの局所系の支配方程式，および回転角評価式を用 いても 2 次の近似解となり得る. 特に, 局所系の式とし
て, a) 微小変位の式やd) の有限ひずみ・有限変位の 式の解に収束する式等, 非常に簡略化した式でも，f) 微小ひずみ・有限変位の式の解および e) 有限ひずみ・ 有限変位の式の解に対し， 2 次の近似解となることは注 目されよう. また, 軸線の伸張変形が無視できる場合は, これを考虑する場合に比へ，微係数の一致性状は向上す るが, 全体としては 2 次の近似解にとよ゙まっている.

一方座標系 I の場合は，すでに文献 1 ）にも述べてい るとおり, 軸線の伸張変形が無視でき, しかも局所系の 式として，b）はり・柱の式や，c）線形化はり・柱の 式を用いる場合のみ， 2 次の近似解で, 他はすべて 1 次 の近似解となる. 1 次の近似解でも, 分割長を十分小さ くしていった場合には, 理論的には収束することが示さ れるが, 実際の数值計算では誤差累積の関係上, 少なく とも 2 次以上の近似解となる必要がある4．この意味で 局所座標系 I の場合は, 軸線の伸張変形が小さいか, こ れを無視できるという前提で, 局所系の式に, b) はり・ 柱の式や c) 線形化はり・柱の式を用いるという場合に 限ってほぼ, 十分な解析が可能である. 特に, 局所系の 
式として，低次非線形のd) の式を用いて有限ひずみ問 題の解析を行う場合ならびに, a) 微小変位の式を用い る場合には局所座標系 II を用いる必要がある.

次に，局所系の支配方程式の差が精度に及ぼす影響に ついて考察する. 各物理量の微係数の収束解に対する一 致性状をみると，局所座標系の差によらず，f）微小ひ ずみ・有限変位の式の解に収束するグループでは，b) はり・柱の式，c）線形化はり・柱の式を用いた場合の， また, g）軸線不伸張の有限変位の式の解に収束するグ ループでは，b）の式を用いた場合の一致性状がそれぞ れ最もよい.なお，軸線不伸張のグループでは，b）の 式を用いた場合とc）の式を用いた場合の差は小さい. 以上の一致性状と取り扱いの容易さを併せて考慮する と, 局所系の式としては, 非線形項を含まず，a）微小 変位の式より若干複雑なだけの c) 線形化はり・柱の式 を用いるのが最も有効であろう．ただ局所座標系 II を用 いる場合には, 前述したように, a) 微小変位の式によっ ても, 収束解に対して 2 次の近似解となるため, 十分な 解析が可能と考えられる.

さらに剛体回転除去後の回転角評価式が解析精度に及 ぼす影響について検討する.この影響は, 局所座標系 I, II を通じて，局所系の式として， b) はり・柱の式と c) 線形化はり・柱の式を用いた場合に現われており，いず れも最も単純な線形の評価式 $\hat{v}_{0}^{\prime}=\hat{\alpha}$ を用いたときの精 度がよいことを示している. したがって, 実際の解析で は，精度と簡便さの両面から，すべて線形の回転角評価 式を用いるのが適当であるといえる，以上の角度評価に 関する結論は, 局所系の支配方程式として, あくまで,

Table 1 に示すような簡略化した式を用いることが前提 で, より精度のよい局所系の支配方程式を用いた場合に は, 当然のこととして, 非線形の評価式により精度が向 上することも考えられる1). しかしながら，b）はり・ 柱の式以上の非線形式を用いると局所系での離散化式自 体を求めるのが困難となり, 支配微分方程式の簡略化を 目的とした剛体変位除去の手法の意味が薄れる.

\section{6. まと め}

通常の剛体変位除去の手法による有限変位解析では, 局所座標系として, Fig. 1 (b) に示す変形後の有限要 素節点を結ぶ割線座標系が最も多く用いられる. 本論文 では, この局所座標系を用いた場合の精度を, 従来採用 されている局所系での各種支配方程式ならびに䍑体回転 除去後の各種回転角評価式の組合せについて理論的に調 べた.さらに, 上記の結果に, すでに文献 1 ) で得られ ているもう 1 つの局所座標系である, Fig. 1 (a) に示す 接線座標系に関する結果に若干追加したものを含め, 平 面骨組解析における実用的な䍑体変位除去の手法の基本
的な精度特性を総合的に検討した。これらの検討から， 平面骨組の有限変位解析に剛体変位除去の手法を適用 し, 効率的な計算を実施するための重要な指針は, ほぼ, 明らかになったと考えられる. 得られた結果を以下にま とめる.

なお，本論文では平面骨組を対象としているが，平面 骨組は立体骨組や板殼の変形を平面内に限定した場合に 相当するので, 得られた結果の大部分は剛体変位除去の 手法による立体骨組や板殼の解析にも適用できるものと 考える.

（1）局所座標系としては，座標系 II を用いた方が， 座標系 I を用いた場合より全体的に精度がよく，従来提 案されているどのような局所系の式や回転角評価式を用 いても 2 次の近似解となり得る.したがって, 通常の剛 性法による解析では,座標系 II を用いるのが有利である. 特に, 局所座標系 II 場合には, a) 微小変位の式や, d) 有限ひずみ・有限変位の式の解に収束する式のような非 常に簡略化した局所系の式を用いる場合にも収束解に対 して 2 次の近似解となることは注目される.

（2）局所座標系 Iは，伝達マトリックス法等で用い られるが,この局所座標系では，f）微小ひずみ・有限 変位の式の解ならびに, e) 有限ひずみ・有限変位の式 の解に対して，いずれの局所系の式を用いても高々 1 次 の近似解である. したがって, これらの場合, 数值計算 では, 誤差が累積し, 十分な解が得られない場合もあり 得る.ただ, 軸線の伸張変形が微小である場合には局所 系の式にb) はり・柱の式や，c) 線形化はり・柱の式 を用いると 2 次の近似解となるため, 有効である.

（３）局所系の支配方程式としては，b）はり・柱の 式の精度が最もよい. しかしながら，c）線形化はり・ 柱の式がほぼ同程度の精度を有していることと, 式の取 り扱いが格段容易であることを考慮すると，実際の解析 では，c）の式を局所系の式として用いるのが有利であ ろう。なお，局所座標系 II を用いる場合には，（1）で 述べた理由により, a) 微小変位の式や, d) 有限ひずみ・ 有限変位の式の解に収束する式を用いた場合も有効であ る.

（4）剛体回転除去後の回転角の評価式としては，局 所座標系 I , II を通じ，線形の評価式を用いた場合の精 度が,他の非線形の評価式を用いた場合より優れている。 したがって, 精度と取り扱いやすさの両面から, 従来の 実用的な解析に用いられている局所系の支配方程式に対 して,すべて線形の回転角評価式を用いるのがよい.

\section{補遗 $\hat{F}_{z i}, \hat{F}_{y i}$ の $N_{i}, V_{i}$ への変換}

ここでは, 局所系の式に b) はり・柱の式，剛体回転 除去後の回転角の評価式に $\hat{v}_{0}^{\prime}=\hat{\alpha}$ を用いた場合を例と 
して説明する.

まず，Table 4 より， $\hat{v}_{0}^{\prime}$ を要素長 $l$ に関するべき級数 展開し，線形の回転角評価式を用いれば,

$$
\begin{aligned}
& \hat{\alpha}_{t}=\frac{x}{2} l+\frac{1}{6 b} \hat{F}_{y l} l^{2}-\frac{x}{24 b} \hat{F}_{z i} l^{3}+O\left(l^{4}\right) \cdots \\
& \text { ここに, } x=M_{i} / b, \quad b=E I
\end{aligned}
$$

式 (A) より, $\sin \hat{\alpha}_{t}, \cos \hat{\alpha}_{t}$ をlのべき級数展開で表 示すると次のようになる.

$$
\begin{aligned}
& \sin \hat{\alpha}_{l}=\frac{x}{2} l+\frac{1}{6 b} \hat{F}_{y l} l^{2}-\left(\frac{x}{24 b} \hat{F}_{z l}+\frac{x^{3}}{48}\right) l^{3}+O\left(l^{4}\right) \\
& \cos \hat{\alpha}_{l}=1-\frac{x^{2}}{8} l^{2}-\frac{x}{12 b} \hat{F}_{y l} l^{3}+O\left(l^{4}\right) \cdots \cdots(\mathrm{B} \cdot \mathrm{a}, \mathrm{b})
\end{aligned}
$$

式 (B) を式 (5) に代入すれば,

$$
\begin{aligned}
\hat{F}_{z t}= & N_{t}-\frac{x}{2} V_{i} l-\left(\frac{x^{2}}{8} N_{t}+\frac{1}{6 b} V_{t} \hat{F}_{y t}\right) l^{2} \\
& -\left(\frac{x}{12 b} N_{i} \hat{F}_{y t}-\frac{x}{24 b} V_{t} \hat{F}_{z i}-\frac{x^{3}}{48} V_{t}\right) l^{3}+O\left(l^{4}\right) \\
\hat{F}_{y t}= & V_{t}+\frac{x}{2} N_{i} l+\left(\frac{1}{6 b} N_{i} \hat{F}_{y t}-\frac{x^{2}}{8} V_{t}\right) l^{2} \\
& -\left\{\left(\frac{x}{24 b} \hat{F}_{z i}+\frac{x^{3}}{48}\right) N_{t}+\frac{x}{12 b} V_{t} \hat{F}_{y t}\right\} l^{3}+O\left(l^{4}\right)
\end{aligned}
$$

上式は $l$ の 1 次項までの展開において, $\hat{F}_{z i}, \hat{F}_{y i}$ は $N_{i}$, $V_{l}$ で表わされているが, それょり高次項では, 係数に $\hat{F}_{z l}, \hat{F}_{\mathbf{y}}$ が含まれている. したがって, 次のような手 法により逐次高次項を $N_{\boldsymbol{l}}, V_{\iota}$ で表わす.

$$
\text { 式 (C) より, }
$$

$$
\begin{aligned}
& \hat{F}_{z t}=N_{t}-\frac{x}{2} V_{i} l+O\left(l^{2}\right) \\
& \hat{F}_{y t}=V_{t}+\frac{x}{2} N_{t} l+O\left(l^{2}\right) .
\end{aligned}
$$

であるから，これを式 (C) の右辺に代入すれば式 (C) は次式のように $l$ の 3 次項まで $N_{i}, V_{t}$ で表わされる.

$$
\hat{F}_{z i}=N_{i}-\frac{x}{2} V_{l} l-\left(\frac{x^{2}}{8} N_{i}+\frac{1}{6 b} V_{i}^{2}\right) l^{2}
$$

$$
\begin{aligned}
& -\left(\frac{x}{8 b} V_{t} N_{t}-\frac{x^{3}}{48} V_{t}\right) l^{3}+O\left(l^{4}\right) \\
\hat{F}_{y t}= & V_{t}+\frac{x}{2} N_{t} l+\left(\frac{1}{6 b} V_{t} N_{t}-\frac{x^{2}}{8} V_{t}\right) l^{2} \\
& -\left(\frac{x}{12 b} V_{t}^{2}-\frac{x}{24 b} N_{t}^{2}+\frac{x^{3}}{48} N_{t}\right) l^{3}+O\left(l^{4}\right)
\end{aligned}
$$

さらに,このようにして得られた $\hat{F}_{z i}, \hat{F}_{y i}$ の 3 次ま での展開式を, 続いて式 (C) の右辺に代入すれば, $l$ の 5 次項まで $N_{b}, V_{l}$ で表わされる.これを繰り返して いけば，理論上無限項まで $N_{i}, V_{\imath}$ で表わされるが, 本 検討で必要なのは初めの数項であり, 上記の操作を高々 数回繰り返せばよい.

1）後藤芳顆・長谷川彰夫・西野文雄 : 平面骨組の有限変位 解析の精度に関する一考察, 土木学会詥文報告集, 第 331 号, pp. 33 44, 1983 年 3 月.

2) Goto, Y., Hasegawa, A. and Nishino, F. : Accuracy and Convergence of the Separation of Rigid Body Displacement for Plane Curved Frames, Proc. of JSCE, No. 344, I-1, pp. 67 77, April, 1984.

3) Goto, Y., Hasegawa, A., Nishino, F. and Matsuura, S. : Accuracy and Convergence of the Separation of Rigid Body Displacements for Space Frames, Proc. of JSCE, No. 356, I -3, pp. 109 119, April, 1985.

4) 後藤芳顯 - 山下時治 - 春日井俊博 - 松浦 聖：平面棒材 の有限変位解析の精度に関する数値的検証, 構造工学詥 文集, Vol. 33 A, pp. 15 26, 1987 年 3 月.

5) Ai, M. and Nishino, F. : On Convergence of Geometrically Nonlinear Discretization at Limit Element Division, Proc. of JSCE, No.374, I-6, Oct., 1986.

6）後藤芳顯・長谷川彰夫 - 西野文雄：阿井正博・村上 淳 共著 “伝達関数法による面内曲げ有限変位問題の解析” への討議, 土木学会論文集, 第 356 号, pp. $583 \sim 585$, 1985 年 4 月.

(1987.4.20 - 受付) 